\title{
Food Control in the Decade of 1990's*
}

\author{
Richard J. Ronk \\ (Product Policy Staff, Center for Food Safety and Applied Nutrition Food and Drug Administration)
}

I want to thank Dr. Tanimura and the organization committee of the meeting for inviting me to Japan. It is a great honor to speak to you on the occasion of the 30th Anniversary of Food Hygiene Association.

Much has happened in the last thirty years to make the food supply of both of our countries as safe as any food supplies in the history of the world. Much is left to be done. We cannot relax. Food safety is quite fragile and requires constant vigilance. Much of the protein we consume is in a fragile balance with nature. Meat, milk, fish, and eggs are considered to always be at great risk from microbiological contamination. While we cannot inspect quality into food, a vigorous government inspection program is always required to make sure that industries Quality Assurrance programs are vigorously and conscientiously carried out. Your Society has meet this challenge well during the past 30 years. I am sure you will meet it well for the next 30 years and far into the future.

Food control programs in the United States, Canada, Japan, and Western Europe have brought about a great deal of food safety in these developed countries. Our citizens can be proud. We have laws which are vigorously enforced in the areas of food sanitation and chemical safety. We have rules that regulate the migration to food of chemicals from packaging materials, animal drugs and pesticides. We establish specifications for food additives. We require that food be truthfully labeled. We

\footnotetext{
* Abstract of Special Lecture Presented at the 59th
} Meeting of the Food Hygienic Society of Japan. guard against adulteration or dilution of food with ingredients of no food value. We are interested in providing the consumer with sound nutritional advice. We have truly reduced many of the uncertainties about food, and yet the consumer, our citizen supervisor in the case of government officials, views our efforts with concern. (We will discuss this consumer concern later as it has profound consequences.)

Food control programs in the United States, Canada, Japan and Western Europe have arguably brought our citizens the safest food supplies in the history of the world. It has been reported that by 1992 all of the National food laws of the twelve countries of the common market will have been harmonized to provide for uniform execution of food protection for all of the people of Europe. This has been accomplished even though we have in these countries many different laws and manage these laws in many different ways.

In my view this has come about in all of these countries because of a common concept of food control. Food control is primarily a government function while food protection is a combination of control by regulatory Agencies and includes industry Quality Assurance programs and consumer education. In both the United States and Japan our food protection systems flow from a strong and continuing tradition.

\section{Food Protection in Japan and the United States}

The Food Sanitation Law of Japan (Law No. 233, December 24, 1947), the cabinet order for Enforcement of Food Sanitation Law of Aug. 31, 1953 and the Enforcement Regulation of Food Sanitation Law July 13, 1948, were remarkable achievements. 
Article one, Chapter one of the Food Sanitation Law of Japan set a goal for all of us to strive to achieve. It anticipates many of the provisions of national laws which precede it.

The purpose of this law is to protect the people from hazards to health which may be caused by consumption of food or drink, and to contribute to the improvement and promotion of public health.

This law takes into consideration in a more comprehensive way the total picture of food enforcement than the U.S. law, The Federal Food Drug and Cosmetic Act. It includes in its scope the prefectures, local health authorities, and research laboratories. It also has a built in advisory committee, the Food Sanitation Investigation Council (Chapter 7).

Although the precise contribution of food regulation in Japan and the United States to the entire public health movement cannot be quantified it has obviously been a major component.

The Japanese food law in my view is in some chemical respects more modern the U.S. law. Our law was most recently framed in 1938 with major amendments in 1954 for pesticides and in 1958 and 1960 for food additives and color additives.

In the chemical safety area require premarket approval for pesticides and food additiveswhich includes packaging ingredients and animal drugs. There is no pre-approval of food formulaes or recipes food standards once establişhed. We do not pre-approve process changes except for low acid canned foods. FDA does give advisory letters or opinions on these subjects.

We publish many specific regulations about our law. When we publish a regulation everyone is free to comment. Everyone means anyone in the world and we must convince our judges that we have considered all of these comments in any final rule we adopt.

Our federal laws do not include our states or prefectures as yours do and our states can have their own rules. We do try to harmonize our state laws by writing model ordinances and codes for the local enforcement officials. Thirtyfive of the fifty states have adopted the model code.

In my view food protection in the Unit States and Japan is not protectionist of our economics but only protects our citizens. In both our countries our concern for the health of our citizens comes first.

\section{Shift in Public Policy}

During the last two decades the picture changed. The perception of food safety, as represented by the print and electronic media, have lead to a public perception that food is not as safe as it was.

During the two decades, our national attentions have shifted from concern about acute disease to chronic degenerative diseases such as cancer and heart disease. These diseases in the United States have replaced acute disease as principal causes of death. Changes in public policy have resulted. Another change is the great emphasis on food safety problems.

This has focused a great deal of attention on imported foods in both of our countries. We do not carry out food inspection of factories outside our country. So when we are asked "How do you know inported food is safe". We are less contain than about our domestic products. The consumer wants more assurance. This has put great presure on all regulators relative to pesticides, food additives, and animal drug residues. It has lead to the pesticide monitoring act of 1988 which is primarily about imported fruits and vegetables.

Recent reports of our Generel Accounting Office (GAO) has also focused on imported can foods, imported wines, and imported cheeses which had a variety of chemical and microbiological contaminants. Tampering or sabotage of chilean grapes and domestic concern for Alar on apples coming at the same time have brought permanent changes to food safety programs in the United States.

This is truely surprising, no one traveling in the United States or Japan worries about the food. In fact world travelers in both our countries come home wanting to sample the cuisine of those countries at home.

While we can understand the perceptions of consumers about food safety, these fears do not seem to be based on sound science. The consumer wants a risk-free association with food-what governments can provide is a reasonably safe 
food environment; one in which the uncertainties surrounding food safety are reduced. There is an element of trust in it, trust that the food control system is working. We say a food is safe when there is a reasonable certainty of no harm. Let us consider a few of these issues:

\section{Microbiological Safety-Present}

There is an apparent resurgence of microbiological hazards in the food supply. The changing environment of food production coincides with the developing ability of microbiological contaminants to appear in new places in the food distribution system. This is somewhat an attribute of new microbiological test system that disprove the efficacy of old quality assurance procedures.

Our recent problems with Listeria monocytogenes in imported soft cheeses and also in domestic cheeses and ice cream is a case in point. The analysis for Listeria monocytogenes took 12 days. There was a necessary enrichment step. Now from start to finish with gene probes the analysis takes $48 \mathrm{hr}$. In the past there was no way to efficiently show that listeria survives in high salt solutions; that it is only stunned by the "rolling boil" of shrimp cooking; that it survives well in the frozen state and even grows at $40^{\circ} \mathrm{F}$ flore refrigerator temperature. Cold does not present the protective factor that we thought. While we had deaths from cheese in the U. S., there were no injuries demonstrated for ice cream products. New technology and better analytical techniques point out new hither to unknown food risks.

Still we know that for foods to be tasty and flavorfully to taste like "Fresh" over-processing to kill microbes causes problem. The wave of the future is for foods to undergo less processing such as atmosphere controlled packaging "Sous Vide". Closer quality control will therefore be required. What changes will our new found capasity bring.

\section{Future Microbiological Safety}

1. In the future Hazard Analysis of Critical Control Points (HAACP) will be a mandated technique of quality assurance which will require Good Manufacturing Practice and Quality Assurance procedure for all prod- ucts from time of production through the entire distribution channel right up to the time of consumer use.

2. There will be changes in farm practices to guard against Salmonella contamination. So called Good Agricultural Practice Regulations.

3. There will be continuous laboratory surveillance of all food production lots of "high risk" foods.

There will be less reliance on traditional inspections. Traditional inspections don't uncover these more difficult microbiological problems. Consumer complaints or laboratory investigator of hospital illness not inspection turns up mots incidences of food born disease. Salmonella in eggs and meat will be attacked at the farm. Feed contamination has caused a reservoir of Salmonella which must be addressed on the farm. Thus more attention by health officials at the farm.

The review of quality control records and continuous laboratory surveillance of foods will be the tools of the future. Countries will ask for oversight of these functions as a condition of importation.

In the United States, we presently have an expert committee helping the Food and Drug Administration work on the concept of critical control point hazard analysis. This concept is quite useful. It depends on a careful analysis of each aspect of the food manufacturing process to assure that the most sensitive safety points are found. It would consider all of the ingredient suppliers and what specification would be required for them.

The facility and plant design should be considered. Storage, testing, and equipment should be all analyzed for critical points. The environment of the plant is examined from a bacteriological stand point. But also vapors, dusting, and cross contamination by personnel. Thermometers, temperature recorders calibration of all equipment are examined. The possibility that screens, can break, knive blades, can shatter, and metal surfaces can be scraped,--are all considered.

Critical people must be considered. Education and control. Do employees use hand washing stations. Possible contamination between raw 
and finished goods.

How are chemicals use in plant? How are they accounted for?

Packaging - the distribution system and finally the consumer. What can be done to defeat all this before consuming the product. Consumer education.

Total control of the critical points of safetyHAACP will be a requirement for food production throughout the decade of the 90's. Countries will ask for on oversight of these functions as a condition for importation of food.

Pesticides-There will be great pressures for alternatives to pesticides and for alternative approaches to farming. In the United States and the world concern about pesticides is at an all time high. Our consumers have a choice between more bugs, less perfect fruits and vegetables, or continued use of chemical pesticides.

In my view consumers and politicians have made the choice that there will be fewer agricultural chemicals. Food quality over the short run will suffer. There will be much greater state certification of how farmers use pesticidesagain farm practice regulations.

\section{Chemical Pesticides: Present and Future}

For chemical pesticides the future is now. While it is a personal opinion, much research world wide indicates that industry is looking for substitutes to chemical pesticides on an accelerated basis. Alternatives will be found. In addition, there will be:

1. Greater control of pesticide use on the farm.

2. On a national basis the introduction of Good Agricultural Use regulations as a requirement for continued registration of more toxic pesticides.

3. Fruits and vegetables with pesticide characteristics genetically placed in plants will present regulators with the challenge of ensuring safety of these products.

\section{The Policy about Food Ingredients}

There is a much stricter enforcement of laws relative to ingredient use. Additives to food are not just considered on the basis of toxicological safety and technological function in food justified at time of approval. Now we also consider any changes in function as requiring reconsi- deration of all uses. There is also postmarket surveillance, a kind of running total of estimated daily intake from all sources.

\section{The Future for Ingredients}

There is great pressure and concern about food ingredients. New technologies of safety assessment will have to be developed.

1. Many ingredients added to food challenge traditional ways of evaluating safety.

2. New approaches to consideration of novel ingredients added to foods are required.

3. There will be greater consideration of the cancer risks presented by food itself, rather than just the ingredients added to food. (Sugimura's work with mutagens in food is instructive).

The Japanese Cancer Institute and Japanese investigators have long demonstrated that, some of the most mutagenic materials in food are the mutagens that result from cooking. Creatine, an essential amino acid in all skeletal tissue (muscle meat), is an essential precursor for Aminoimidazoazaarene (AIA) formation. The so-called $I_{Q}$ and methyl $l_{Q}$ mutagens in meat extracts are highly mutagenic. These findings will cause great pressure on the reaction flavors which are products of Millard reaction of amino acids, fats and sugars. It is also an indicator that much of the risk of cancer from food is natural.

It points out the folly of traditional food additives rather than food itself as the principal source of cancer risk.

Food biotechnology will come into its own; progressing from where it began 25 years ago in fermentation enzymes to recomibinant DNA techniques.

\section{Nutritional Safety of the Food Supply}

Concern about heart disease and health consciousness will change the character of food labeling and advertising.

1. Health claims on food labels and in advertising will be closely monitored by the government.

2. Nutritional status will be closely monitored as part of national disease prevention programs.

3. Nutritional labeling will be mandatory in all countries. 
4. Food Standards will be revised from protection of the consumer from economic fraud to reflect a greater influence on nutritional safety.

5. Special dietary foods will require premarket approval.

The Japan Food Hygienic Society has been a key agent in the establishing of food safety policy in Japan in the past and will continue to do so in the future. It is the hope of all that the influence of food safety scientists world-wide will influence national legislators to continue to make sound science the basis of national food policy. Sound science is the foundation of true consumer protection. 